\title{
Multi-Level Anterior Cervical Decompression in Multi-Level Cervical Spondylotic Myelopathy without Extending the Corpus Resection: A Cadaveric Study of a Novel Surgical Technique
} \author{
Buruc ERKAN ${ }^{4}$, Nail DEMIREL ${ }^{5}$, Selcuk OZDOGAN ${ }^{6}$ \\ ${ }^{1}$ Haseki Training and Research Hospital, Neurosurgery Clinic, Istanbul, Turkey \\ ${ }^{2}$ Gaziosmanpasa Training and Research Hospital, Neurosurgery Clinic, Istanbul, Turkey \\ ${ }^{3}$ Koc University Hospital, Department of Neurosurgery, Istanbul, Turkey \\ ${ }^{4}$ Basaksehir City Hospital, Neurosurgery Clinic, Istanbul, Turkey \\ ${ }^{5}$ Istanbul Training and Research Hospital, Neurosurgery Clinic, Istanbul, Turkey \\ ${ }^{6}$ Adatip Hospital, Neurosurgery Clinic, Istanbul, Turkey
}

Tahsin SAYGI ${ }^{1}$, Omer OZDEMIR ${ }^{2}$, Oguz BARAN ${ }^{3}$, Sevket EVRAN ${ }^{1}$, Ahmet KAYHAN ${ }^{1}$, Muhammet Arif OZBEK ${ }^{1}$,

Corresponding author: Tahsin SAYGI tahsinsaygi@yahoo.com

\section{ABSTRACT}

AIM: To perform three-level decompression with a single-level corpectomy by modifying the fusion with anterior cervical corpectomy (ACC-F) method on a cadaver.

MATERIAL and METHODS: The anterior cervical region of four whole-head cadavers was dissected. The corpectomy was performed under a surgical microscope with a MT4-20+ ultrasonic bone dissector (UBD) tip. Superior and inferior decompression were conducted and viewed with a $70^{\circ}$ neuroendoscope using two types (vertically and horizontally oriented) of specially designed 23 mm-long, $90^{\circ}$-angled UBD tips.

RESULTS: After neck dissection and the removal of the thyroid and cricoid cartilages, C5 corpectomy and adjacent-level discectomies were performed. Following discectomy and corpectomy, superior and inferior decompression were conducted with specially designed UBD tips and viewed with a $70^{\circ}$ neuroendoscope. A three-level anterior cervical decompression was provided with a single-level corpectomy.

CONCLUSION: This study demonstrated that two more level decompression is possible with a single-level corpectomy in the cervical region using the new technique.

KEYWORDS: Cervical, Spondylosis, Posterior longitudinal ligament ossification, Minimally invasive approach, Multi-level decompression

ABBREVIATIONS: ACAF: Anterior controllable antedisplacement fusion, ACC-F: Anterior cervical corpectomy with fusion, ALL: Anterior longitudinal ligament, CSM: Cervical spondylotic myelopathy, CT: Computed tomography, MRI: Magnetic resonance imaging, PLL: Posterior longitudinal ligament, SCM: Sternocleidomastoid muscle, UBD: Ultrasonic bone dissector

Tahsin SAYGI (D): 0000-0002-3300-1582

Omer OZDEMIR (1): 0000-0003-3783-0203

Oguz BARAN : 0000-0002-2345-4318
Sevket EVRAN $\quad$ (1) : 0000-0003-1041-252X

Ahmet KAYHAN $\quad$ (1) : 0000-0001-6549-8303

Muhammet Arif OZBEK (1D): 0000-0002-1847-2562
Buruc ERKAN

(10): 0000-0001-8586-0613

Nail DEMIREL (1): 0000-0001-8303-1504

Selcuk OZDOGAN (10) : 0000-0003-2888-8091 


\section{INTRODUCTION}

$\mathrm{T}$ There are three approaches for the surgical treatment of cervical spondylotic myelopathy (CSM), namely, the anterior, posterior, and combined approaches, but the issue of which among these approaches is optimum remains controversial. Many studies comparing these approaches can be found in the literature (23). The anterior-approach surgical methods in treating CSM include fusion with anterior cervical discectomy (ACD-F) and fusion with anterior cervical corpectomy (ACC-F). The posterior-approach surgical procedures include laminectomy without fusion (LAMI), laminectomy with fusion (LAMI-F), and laminoplasty (LAMP) (1). When deciding which surgical approach to use, the following criteria are considered: compression side (ventral or dorsal) (22), cervical alignment, instability (23), number of affected levels (1), patient's age and general condition (11), and method used by the surgeon (1). One of the most debated criteria for deciding the optimum surgical technique is the number of levels that are affected, especially when this number is $\geq 3$, and deciding on the optimum surgical technique has become a matter of debate in the literature (5). Among these approaches, the ACC-F can be performed safely in treating CSM up to two levels, but not three or more levels $(9,20,28,32,34)$. If decompression is required in three or more levels, posterior stabilization is suggested because it results in lesser serious complications such as material failure $(8,9,28,34)$ than other approaches.

In this study, a three-level decompression was performed with a single-level corpectomy by modifying the ACC-F method on a cadaver. This study contributed to the literature by presenting a new method of decompression with a minimally invasive approach.

\section{MATERIAL and METHODS}

Four whole-head specimens were used in this study. These specimens were fixed in a $10 \%$ formalin solution for at least three weeks. A silicone injection procedure was performed using the technique described by Shimizu et al. (30). The specimens were preserved in a $75 \%$ alcohol solution between dissections. Computed tomography (CT) (GoldSeal Optima CT660 ${ }^{\circledR}$, GE Healthcare, GENERAL ELECTRIC COMPANY, Boston, USA) scan and magnetic resonance imaging (MRI) (MAGNETOM Aera 1.5T ${ }^{\circledR}$, Siemens Healthcare Inc., Erlangen, Germany) were performed on all the cadavers before dissection. The anterior cervical regions of the cadavers were dissected with a Zeiss surgical microscope (Carl Zeiss Meditec AG $^{\circledR}$, Jena, Germany) using 6-40x magnification. The anatomic structures were shown step by step until the prevertebral space was reached. After reaching the prevertebral area, level determination was made with a C-arm fluoroscopy (Ziehm Solo mobile C-arm, Ziehm Imaging, Nurnberg, Germany). Corpectomy was performed under a surgical microscope with an MT4-20+ ultrasonic bone dissector (UBD) tip (PIEZOSURGERY Plus ${ }^{\circledR}$, Mectron, Carasco, Italy). After the corpectomy, superior and inferior decompressions were conducted and viewed with the $70^{\circ}$ HOPKINS II neuroendoscope (Karl Storz Endoskope, Tuttlingen, Germany) using two types (vertically and horizontally oriented) of specially designed 23-mm-long, $90^{\circ}$-angled UBD tips. Following the decompressions, stabilization was provided with an anterior cervical corpectomy cage and plate (Osimplant ${ }^{\circledR}$, Ankara, Turkey). Each step of the dissection was photographed with a Canon EOS 700D camera (Canon, Ota City, Tokyo, Japan). Superior and inferior decompressions were also photographed with a neuroendoscope. Fluoroscopic, CT, and MRI scans of the cervical region were performed postoperatively.

\section{RESULTS}

CT scan and MRI of the cervical region of the cadaver were performed before dissection (Figure 1A, B). Anterior cervical dissection was started in the supine position following preoperative radiological imaging (Figure 1C). In the first stage, the subcutaneous tissues were revealed by removing the skin in the area between the midline, mandibular ramus, sternocleidomastoid muscle (SCM), and clavicle (Figure 1D). The submandibular gland, SCM, supra-infrahyoid muscles, anterior jugular vein, and facial artery were revealed after removing the subcutaneous tissues and the platysma (Figure
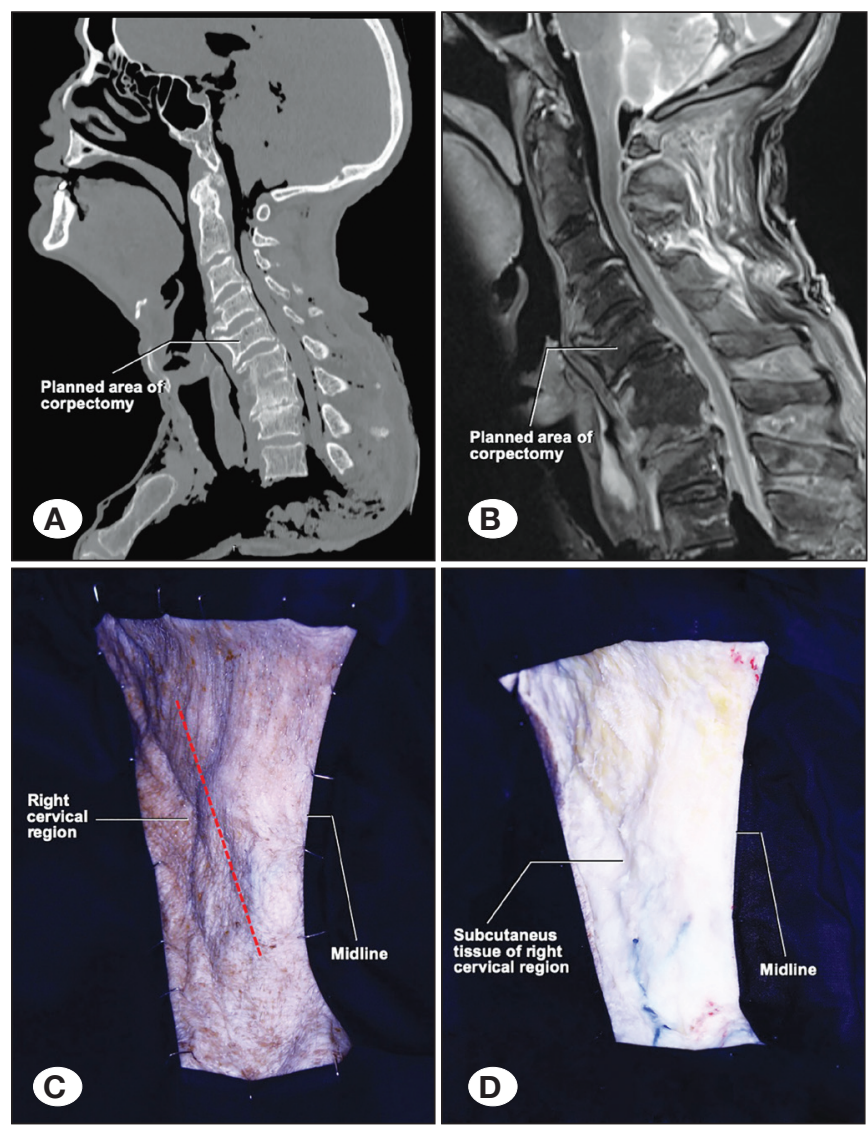

Figure 1: A) A preoperative sagittal CT image of the cervical region. B) A preoperative sagittal T2-weighted MRI of the cervical region. C) Viewing the right cervical region of the patient in the supine position before starting the dissection. The red-dotted line shows the skin incision. D) Viewing the subcutaneous tissue revealed by removing the skin in the area between the midline, mandibular ramus, sternocleidomastoid muscle (SCM), and clavicle in the right cervical region. 
2A). After this step, dissection was continued in the infrahyoid region. One of the infrahyoid muscles, the sternohyoid muscle, was cut and tilted over superiorly and inferiorly. The right omohyoid muscle was excluded to the right, the bilateral thyrohyoid muscles were excluded to right and left, and the anterior jugular vein was cut and tilted over superiorly and inferiorly. In this way, the thyroid and cricoid cartilages were revealed (Figure 2B). Finally, the thyroid and cricoid cartilages were removed to reach the prevertebral area (Figure 2C). After reaching the prevertebral area, two marker pins were inserted into the two disk spaces, and an X-ray scan was performed with a C-arm fluoroscope to determine the level, which was verified to be at the corpus level of C5 as planned preoperatively (Figures 2D, 3A). The removal of the anterior longitudinal ligament (ALL) revealed the C5 corpus
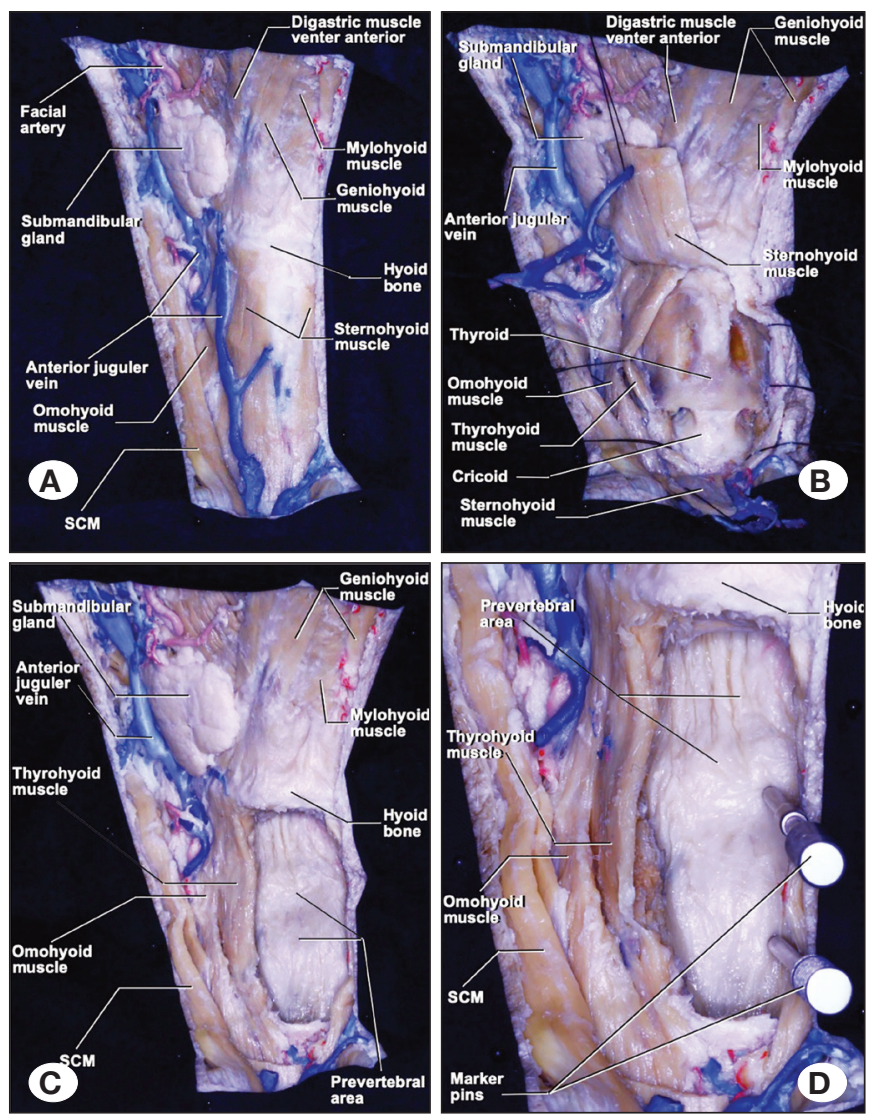

Figure 2: A) Viewing the submandibular gland, sternocleidomastoid muscle (SCM), supra-infrahyoid muscles, anterior jugular vein, external jugular vein, and facial artery revealed by removing the subcutaneous tissues and the platysma in the right cervical region. B) Viewing the thyroid and cricoid cartilages in the infrahyoid region revealed by tilting over the sternohyoid muscle to the superior and inferior, excluding the right omohyoid muscle to the right, excluding the bilateral sternothyroid muscles to the right and left, and tilting over the anterior jugular vein to the superior and inferior. C) Viewing the prevertebral area revealed by removing the thyroid and cricoid cartilages. D) Viewing the preparation stage of the patient for level determination by C-arm fluoroscopy; two marker pins have been inserted into the disc spaces. with the adjacent disk spaces of C4-5 and C5-6 (Figure 3B). Then, C4-5 and C5-6 discectomies were performed. Following the discectomies, C5 corpectomy was conducted using the corpectomy tip of the UBD. The cervical dura was revealed by removing the posterior longitudinal ligament (PLL) (Figure 3C). Following the C5 corpectomy and discectomies, cervical CT scan was performed (Figure 3D). As the last stage of decompression in the study, superior and inferior decompressions were conducted with two types (vertically and horizontally oriented) of specially designed 23-mm-long, $90^{\circ}$-angled UBD tips (Figure 4A, B) and viewed with a $70^{\circ}$ neuroendoscope (Figure 4C). For the superior decompression, C4 posterior corpectomy with a thickness of 2-3 mm, C4 posterior longitudinal ligamentectomy, osteophytectomy, and C3-4 posterior partial discectomy were performed (Figure $4 \mathrm{D}, \mathrm{E})$. The sufficiency of the superior decompression was controlled by perioperative fluoroscopic scanning (Figure 4F). For the inferior decompression, C6 posterior corpectomy with a thickness of 2-3 $\mathrm{mm}, \mathrm{C} 6$ posterior longitudinal ligamentectomy, osteophytectomy, and C6-7 posterior partial discectomy was performed (Figure 5A, B). The sufficiency of the inferior decompression was controlled by perioperative fluoroscopic scanning (Figure 5C). After the decompression
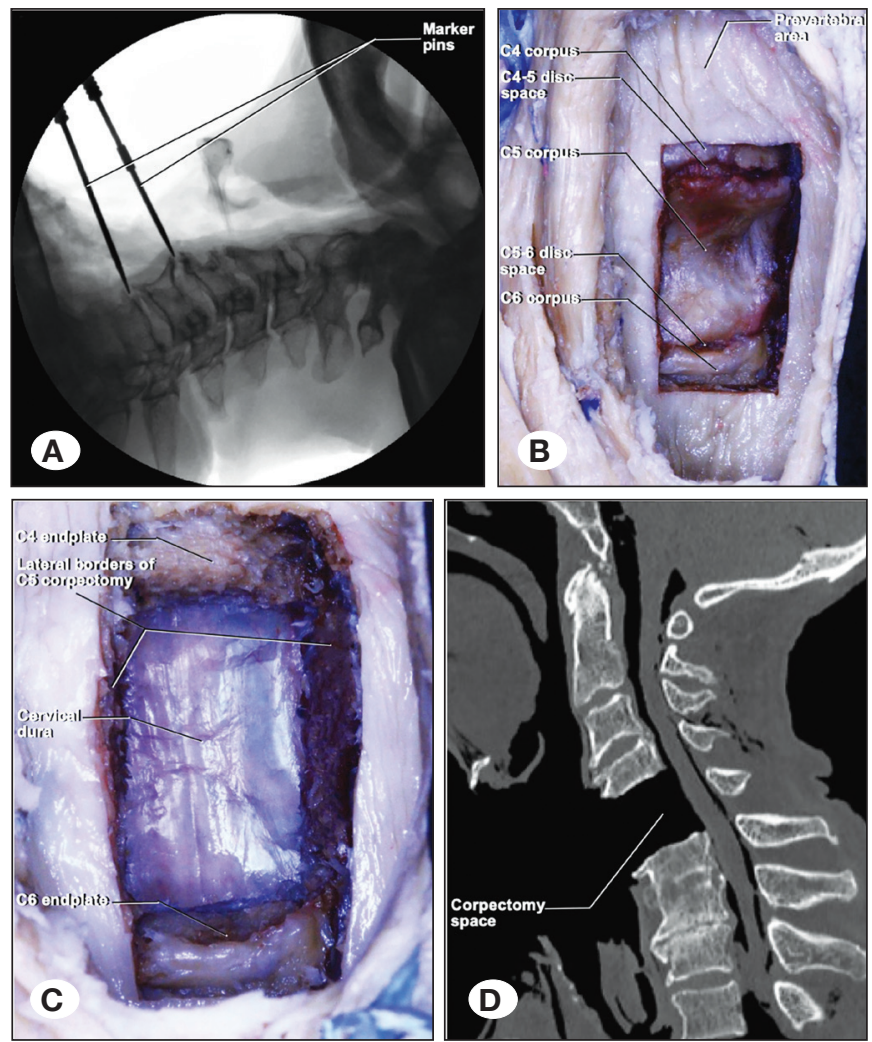

Figure 3: A) A lateral X-ray images of the patient that verify the corpus between the marker pins as the C5 corpus. B) Viewing the $\mathrm{C} 5$ corpus and adjacent disc spaces revealed by removing the ALL. C) A C5 corpectomy was performed in addition to the discectomies of the adjacent levels to reveal the cervical dura. D) A sagittal CT image of the cervical region taken after the corpectomy and discectomy stages. 
stage was completed, postoperative CT (Figure 6A-C) and MRI (Figure 7A-C) scans were performed. Stabilization was provided with a cervical corpectomy cage and plate (Figure
7D). The summary of this novel approach is illustrated in Figures 8A-C, 9A-D.

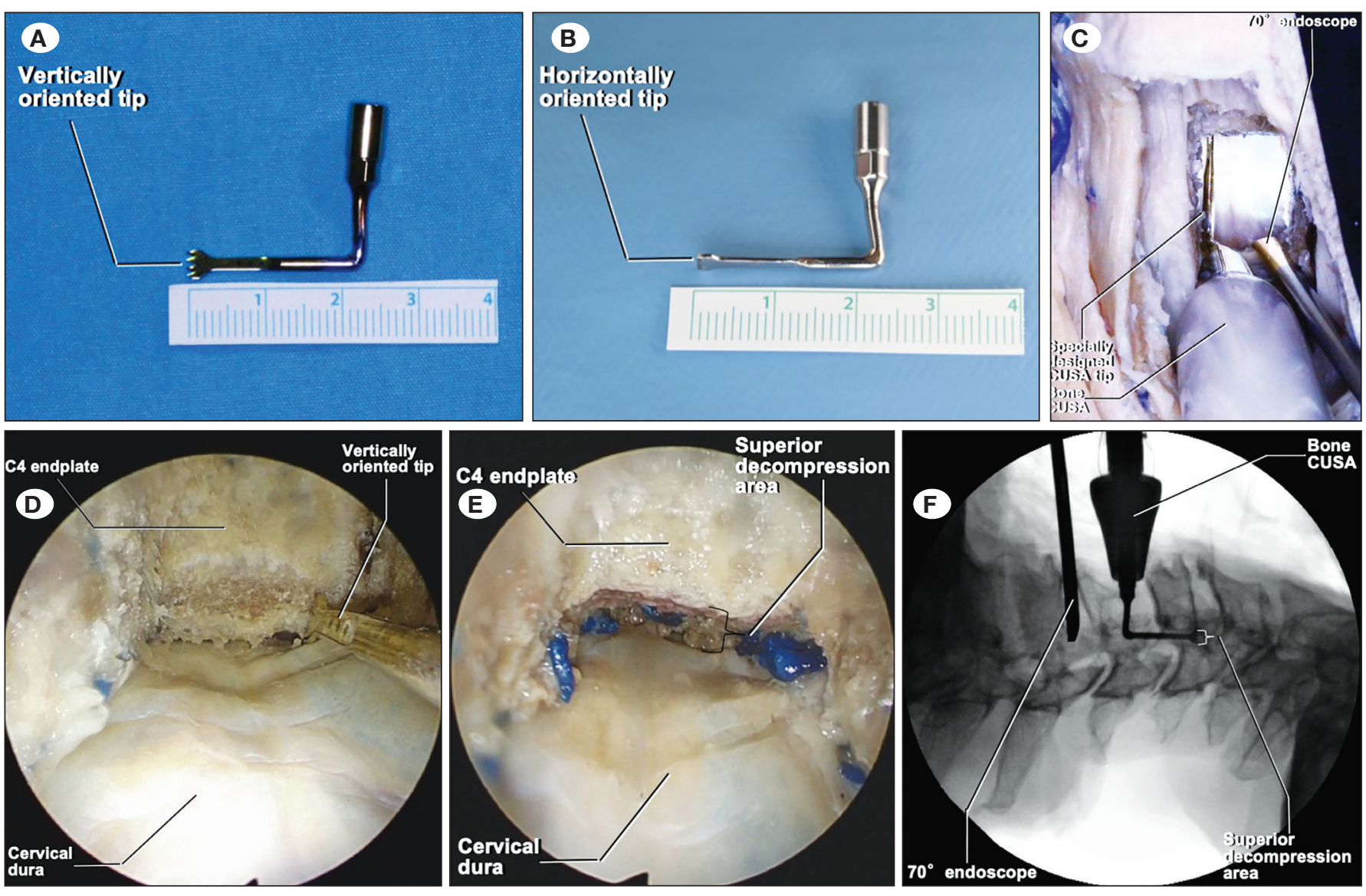

Figure 4: A) View of the specially designed $23-\mathrm{mm}$-long, $90^{\circ}$-angled, and vertically oriented UBD tip. B) View of the specially designed 23-mm-long, $90^{\circ}$-angled, and horizontally oriented UBD tip. C) View of the superior decompression stage with a $70^{\circ}$ neuroendoscope and a specially designed UBD tip. D) Endoscopic view before starting the superior decompression step with a vertically oriented UBD tip. E) Endoscopic view of the superior decompression stage. The bone with a 2-3-mm thickness was taken from the posterior aspect of the $\mathrm{C} 4$ corpus. F) A lateral X-ray image taken after the completion of the superior decompression stage. The decompression extends to the superior edge of the $\mathrm{C} 4$ corpus.
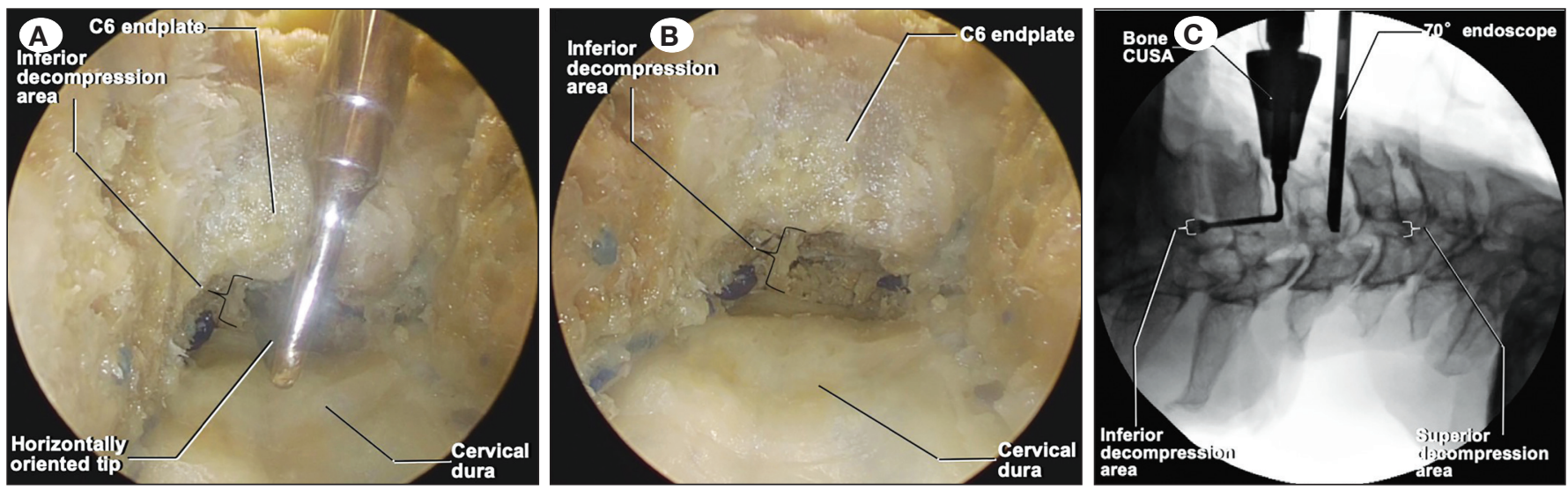

Figure 5: A) Endoscopic view of the inferior decompression step with a horizontally oriented UBD tip. The bone with a 2-3-mm thickness was taken from the posterior aspect of the C6 corpus. B) Another endoscopic image taken during the inferior decompression stage. C) A lateral X-ray image taken after the completion of the inferior decompression stage. The decompression extends to the inferior edge of the $\mathrm{C} 6$ corpus. 

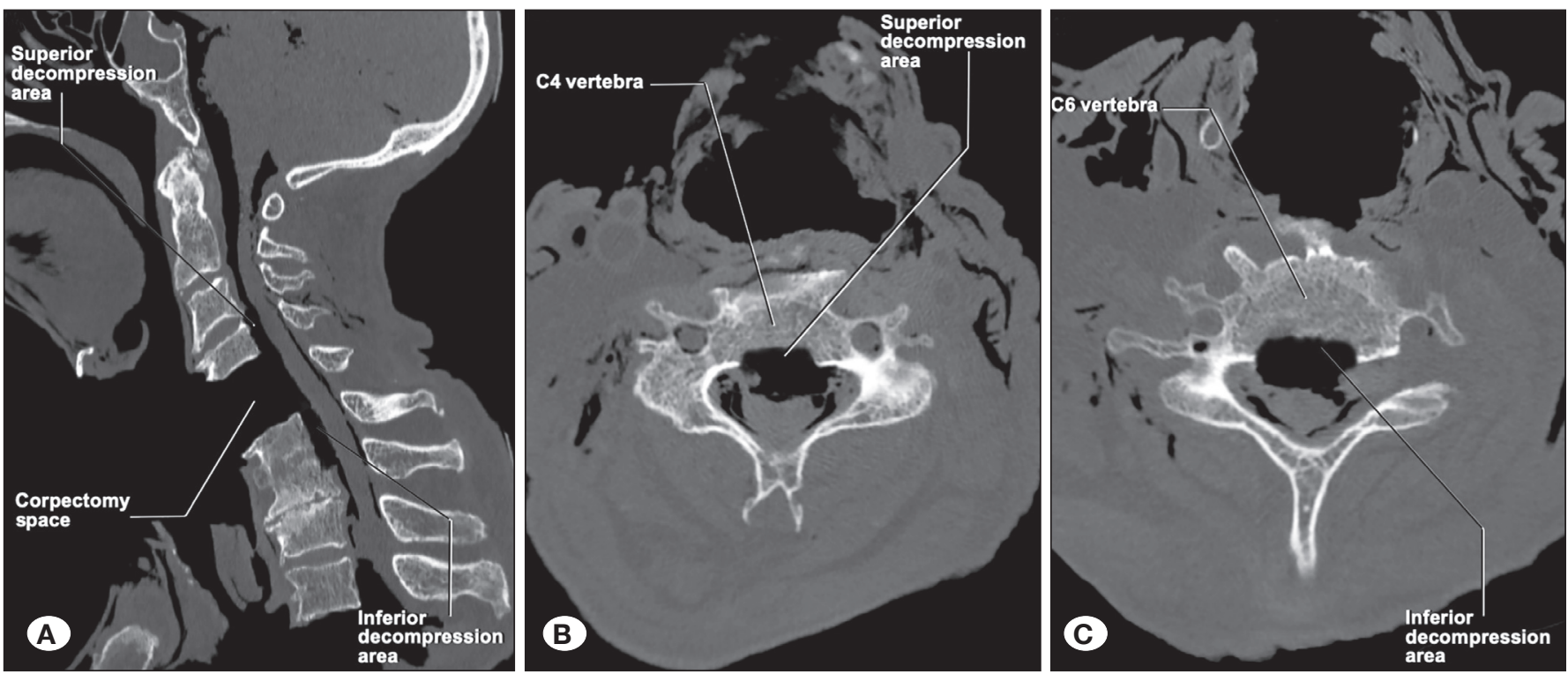

Figure 6: A) A sagittal CT scan of the cervical region after the completion of the decompression stage shows the amount of decompression. B) An axial CT scan of the C4 corpus level shows the amount of superior decompression. C) An axial CT scan of the C6 corpus level shows the amount of inferior decompression.
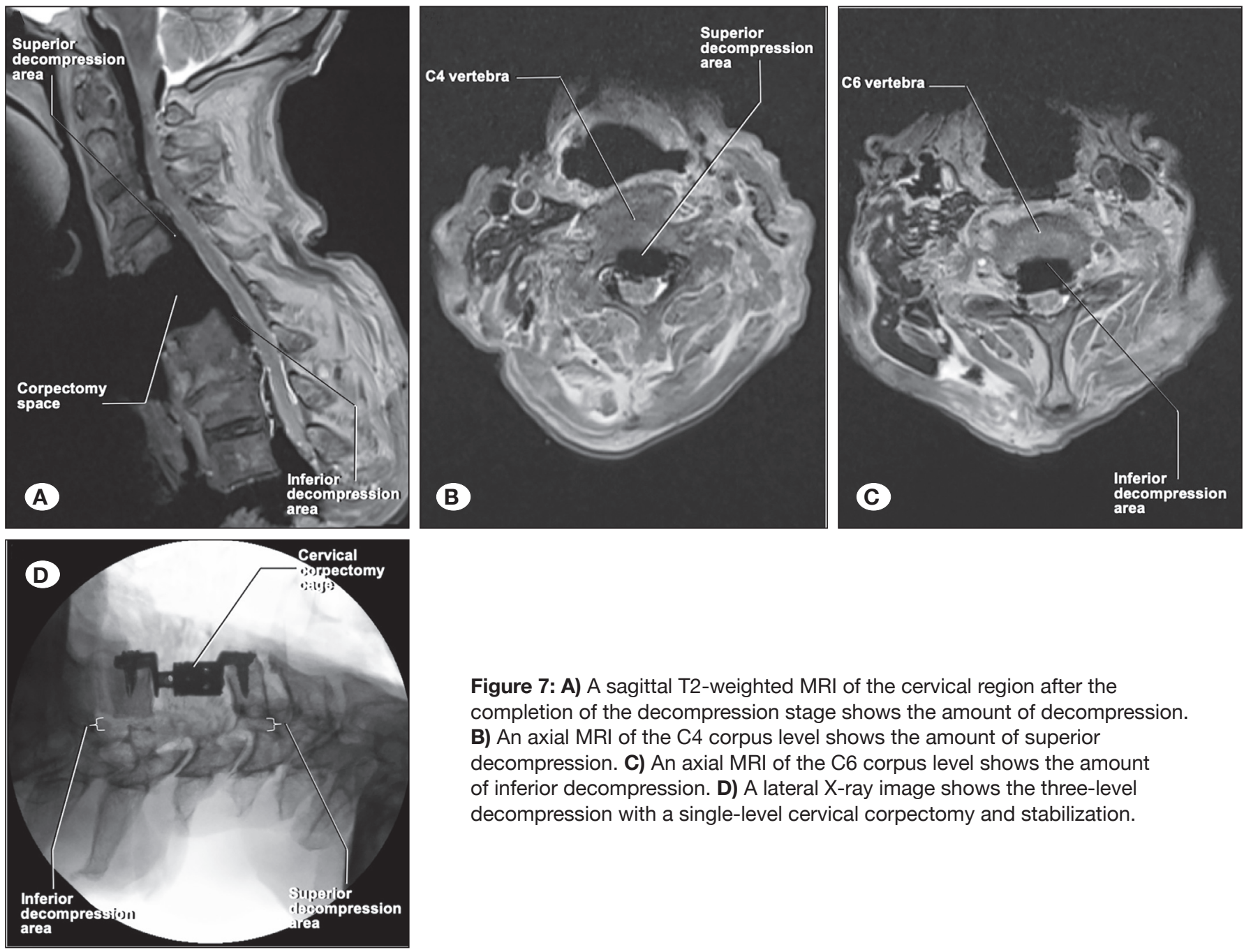

Figure 7: A) A sagittal T2-weighted MRI of the cervical region after the completion of the decompression stage shows the amount of decompression. B) An axial MRI of the C4 corpus level shows the amount of superior decompression. C) An axial MRI of the C6 corpus level shows the amount of inferior decompression. D) A lateral X-ray image shows the three-level decompression with a single-level cervical corpectomy and stabilization. 


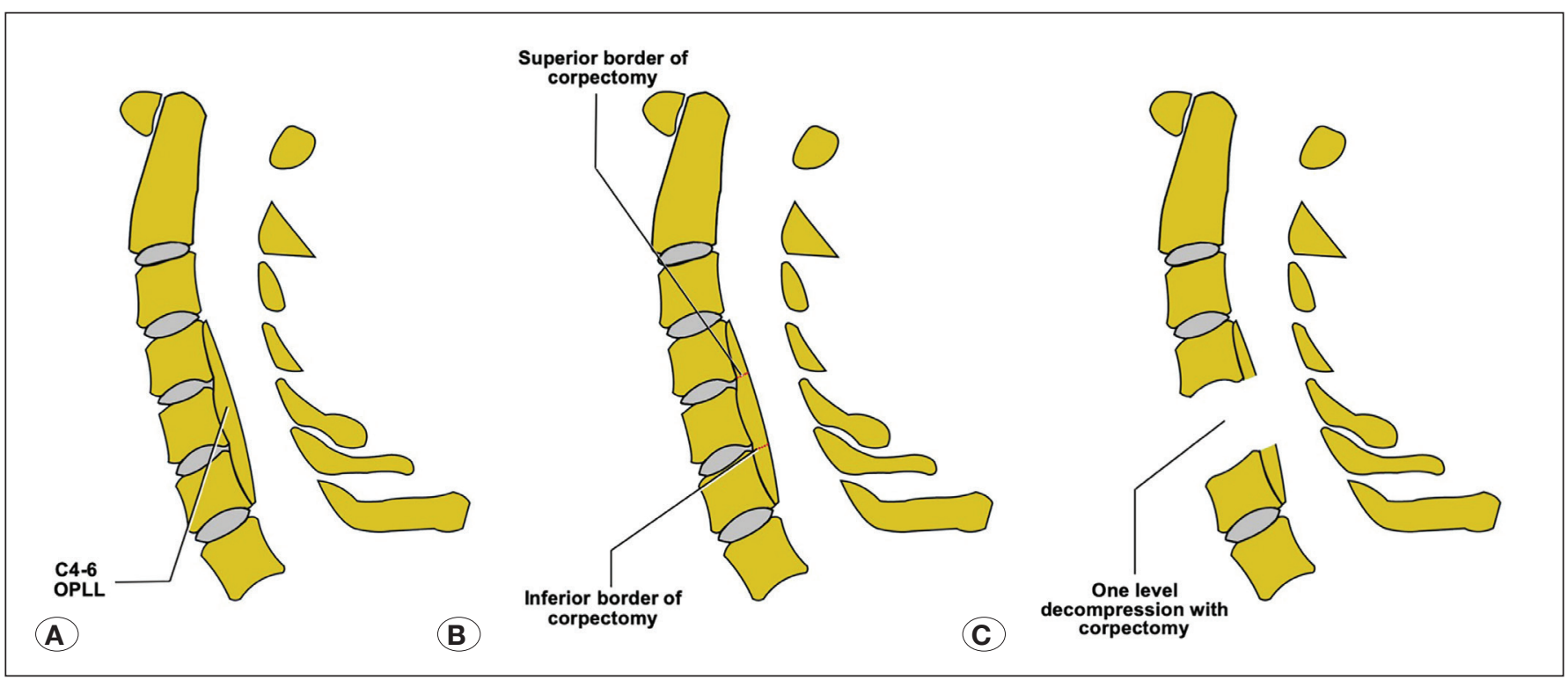

Figure 8: Illustration of the surgical approach. A) Preoperative sagittal view of the patient with continuous-type OPLL extending from C4 to C6. B) Planning the corpectomy stage; the red-dashed lines show the boundary of the corpectomy. C) A C5 corpectomy was performed, and the OPLL behind the C5 corpus was removed.

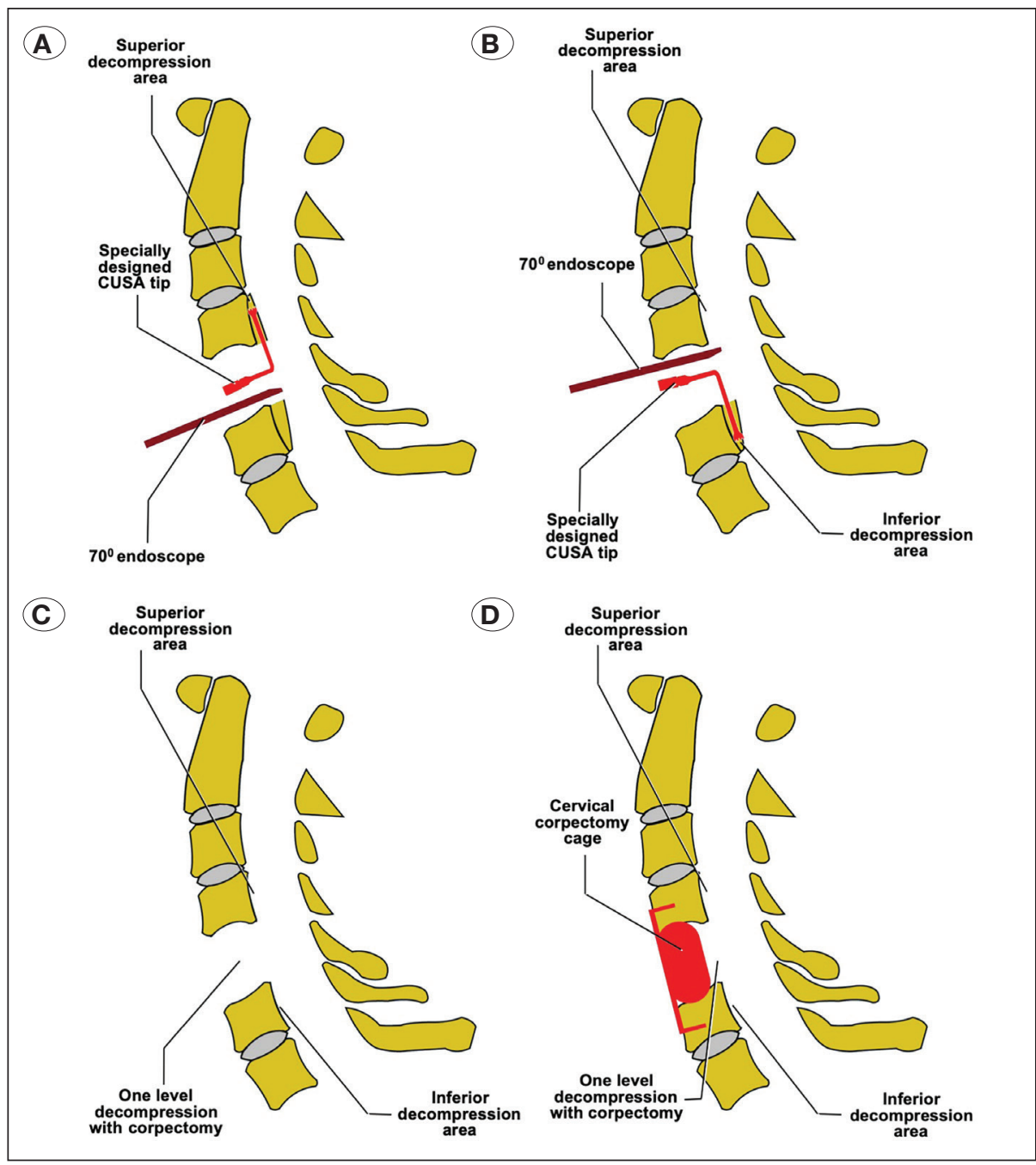

Figure 9: Illustration of the

surgical approach. A) The superior decompression stage shows the removal of the OPLL behind the C4 corpus with a specially designed UBD tip and viewing with a $70^{\circ}$ neuroendoscope. B) The inferior decompression stage shows the removal of the OPLL behind the C6 corpus with a specially designed UBD tip and viewing with a $70^{\circ}$ neuroendoscope. The superior decompression stage is completed here. C) Sagittal view of the patient taken after the completion of the decompression stages. D) Sagittal view of the patient taken after the completion of the decompression and stabilization stages. 


\section{DISCUSSION}

In the literature, there is no consensus on the surgical method to be selected in treating multilevel CSM, and many studies have compared anterior and posterior surgical approaches. For example, studies in which ACD-F and LAMI-F were compared in treating multilevel CSM reported a further improvement in quality of life in patients after ACD-F (13), with ACD-F being more cost-effective than $\operatorname{LAMI}-\mathrm{F}(13,36)$. In a meta-analysis study, Wang et al. compared ACC-F with posterior-approach decompressive surgery in a multilevel PLL ossification (OPLL) and reported that patients had a better Japanese Orthopedic Association scores after the anterior-approach surgeries, but the surgeon recommended the anterior approaches to be used when dealing with complications because of the higher complication rate in anterior-approach surgeries (35). In the study of Chen et al., ACC-F was compared with LAMI-F and LAMP in a multilevel OPLL, and ACC-F was found to be more effective because of the direct removal of the ossified ligament compared with the posterior approaches, and complications could be reduced and surgery could be performed safely with good surgical skills (6). Tani et al. compared LAMP with anterior subtotal corpectomy with fusion in OPLL and found that anterior decompression was both safer and more effective than posterior decompression in patients with occupying ratios of $50 \%$ or more (31). In various studies supporting anterior-approach surgeries related to the occupying ratio in OPLL, this rate was reported to be over $60 \%$ $(12,16,17)$. In another study related to OPLL, calcified foci continued to grow after LAMI because of the instability caused by the removal of posterior elements, and the most successful decompression was obtained by removing the ossified mass with the anterior approach (33). Chiba et al. reported that OPLL continued to progress after open-door laminoplasty (7). Sakai et al. compared anterior decompression and fusion with LAMP in OPLL and found that the neurological improvement after both approaches was similar but that the rate of progression of OPLL was higher in the patients who underwent LAMP than in those who underwent the anterior approach (26). Anterior approaches were suggested to be preferred in the case of massive OPLL (26). Park et al. compared the reoperation rates after anterior and posterior approaches in degenerative cervical spondylosis and found that the reoperation rates after the posterior approaches in CSM were higher than those after the anterior approaches (25). Accordingly, concluding that anterior-approach surgical procedures in treating CSM are more effective and should be preferred than posterior-approach ones is possible. More studies have been conducted showing that the anterior approaches in treating CSM or OPLL are more effective than the posterior approaches $(14,18)$. Conversely, there are studies indicating that the posterior approaches are more effective than the anterior approaches and that both procedures are effective with similar success rates or that the posterior approaches are less complicated. For example, in studies comparing the anterior and posterior approaches in treating CSM, both approaches were shown to be equally effective based on the patients showing similar neurological recoveries $(3,10,11,19,21,27,40)$. However, because of the higher complication rates in the anterior-ap- proach surgical procedures $(10,21,27,40)$, reoperation rates were reported to be higher $(21,27)$. The aforementioned studies proved that many studies support both anterior-approach and posterior-approach surgical options in treating multilevel CSM or OPLL. This situation also proves that the type of surgical approach to be selected is still a subject of debate in the literature. Another important issue regarding the anterior-approach and posterior-approach surgical options is the existence of the criteria that restrict the surgical procedure to be selected. According to Yamazaki et al., cervical lordosis below $10^{\circ}$, kyphotic alignment, thickness of more than $7 \mathrm{~mm}$, and spinal stenosis of more than $50 \%$ in OPLL are the criteria limiting the use of the posterior approaches (37). The anterior surgical approaches cannot be applied in cases in which the compression is from the dorsal aspect (22), but they can be applied up to three levels $(9,11,20,23,32,39)$. When the criteria limiting the use of anterior-approach and posterior-approach surgeries are compared, the number of criteria limiting the utility of posterior-approach surgeries is clearly higher than that restricting the use of anterior-approach surgeries. Note that anterior-approach surgeries can be performed in all types of spinal alignment. Numerous modifications have been developed in anterior-approach surgeries to reduce their complications because of this important situation and the direct removal of the compression. Therefore, the number of anterior-approach surgical options is higher than that of the posterior-approach ones because of the developed modifications. As mentioned above, the posterior-approach surgical options are only LAMI, LAMI-F, and LAMP. The anterior-approach surgical options include ACD-F, anterior cervical disc replacement, anterior cervical median corpectomy and fusion (2), anterior cervical oblique corpectomy (4), open-window corpectomy and fusion (24), and fusion with an anterior pedicle screw after anterior cervical corpectomy (15). Although the anterior surgical approach has many options, studies in this area are still ongoing. In a recent study by Yang et al., a new surgical technique called anterior controllable antedisplacement fusion was added to the anterior-approach surgical options in OPLL (38). In this study, anterior-approach surgeries were considered more effective because of the direct removal of compression in multilevel OPLL, and they focused on the idea of disabling the number of affected levels, which is one of the most important factors limiting the use of anterior-approach surgeries. Thus, with a less invasive approach, more decompression was performed. Generally, performing ACC-F in three or more levels significantly increases the rate of graft or instrument failure compared to when it is performed in two or less levels; therefore, posterior fusion is recommended in addition to ACC-F when dealing with three levels and more (28). However, in the series of Saunders et al., a four-level corpectomy in CSM could be performed safely without morbidity, but the long-term results were not presented (29). Therefore, in this case, how safe four-level corpectomy is was not known. The number of levels affected, which is the most important criterion restricting the use of anterior-approach surgeries, is an important obstacle to be overcome in multilevel CSM or OPLL. In the current study, using the surgical technique developed to overcome this obstacle, the possibility of decompression of two or more levels occurred in addition to 
the decompressed level after corpectomy. The study presents short-level instrumentation as an advantage, which reduces the percentage of material failure. Another important advantage presented in this study is that if the dimensions of the UBD tip and endoscope are sufficiently reduced, performing decompression of two or more levels with only discectomy without corpectomy is possible. Anterior decompression to the $\mathrm{C} 2$ can also occur using the described technique. This study may be criticized because of the possibility of spinal cord compression during the superior and inferior decompression during dissection. The authors only applied force to the OPLL with a $90^{\circ}$-angled UBD tip in the cranial and caudal directions. During the superior and inferior decompressions, putting the bone in pieces was not coercive because the two types of UBD tips (vertically and horizontally oriented) divided the bone to millimetric squares, thus causing easy breakage. The superior and inferior decompressions can also be performed by a gap formed by removing the posterior part of the corpus. Moving the OPLL mass through the gap provides the superior and inferior decompressions as an alternative way. Some cases that had dural ossifications associated with OPLL may be difficult to treat using this technique, but cutting the calcification with a horizontally oriented UBD tip will overcome this obstacle.

\section{CONCLUSION}

This study demonstrated a new technique making decompression of two or more levels possible with a singlelevel corpectomy in the cervical region. Although this study was performed on a cadaver, the authors consider this technique to be useful in treating multilevel CSM patients. Therefore, further studies are needed.

\section{REFERENCES}

1. Alvin MD, Lubelski D, Benzel EC, Mroz T: Ventral fusion versus dorsal fusion: Determining the optimal treatment for cervical spondylotic myelopathy. Neurosurg Focus 35:E5, 2013

2. Banerji D, Acharya R, Behari S, Chhabra DK, Jain VK: Corpectomy for multi-level cervical spondylosis and ossification of the posterior longitudinal ligament. Neurosurg Rev 20(1):25-31, 1997

3. Bourgonjon B, Duerinck J, Moens M, D'Haens J: Comparison of the effect of anterior and posterior neurosurgical treatment for cervical spondylotic myelopathy: A clinical outcome. Acta Neurol Belg 119(4):585-593, 2019

4. Bruneau M, Cornelius JF, George B: Multilevel oblique corpectomies: Surgical indications and technique. Neurosurgery 61 Suppl 3:106-112, 2007

6. Chen H, Liu H, Meng Y, Wang B, Gong Q, Song Y: Short-term outcomes of anterior fusion-nonfusion hybrid surgery versus posterior cervical laminoplasty in the treatment of multilevel cervical spondylotic myelopathy. World Neurosurg 116: e1007-e1014, 2018

5. Chen Y, Guo Y, Lu X, Chen D, Song D, Shi J, Yuan W: Surgical strategy for multilevel severe ossification of posterior longitudinal ligament in the cervical spine. J Spinal Disord Tech 24(1):24-30, 2011
7. Chiba K, Ogawa Y, Ishii K, Takaishi H, Nakamura M, Maruiwa $\mathrm{H}$, Matsumoto $\mathrm{M}$, Toyama $\mathrm{Y}$ : Long-term results of expansive open-door laminoplasty for cervical myelopathy-average 14year follow-up study. Spine (Phila Pa 1976) 31(26):2998-3005, 2006

8. Dalbayrak S, Yilmaz M, Naderi S: "Skip" corpectomy in the treatment of multilevel cervical spondylotic myelopathy and ossified posterior longitudinal ligament. J Neurosurg Spine 12(1):33-38, 2010

9. Edwards CC, Riew KD, Anderson PA, Hilibrand AS, Vaccaro AF: Cervical myelopathy. current diagnostic and treatment strategies. Spine J 3(1):68-81, 2003

10. Edwards CC 2nd, Heller JG, Murakami H: Corpectomy versus laminoplasty for multilevel cervical myelopathy: An independent matched-cohort analysis. Spine (Phila Pa 1976) 27(11):1168-1175, 2002

11. Fehlings MG, Barry S, Kopjar B, Yoon ST, Arnold P, Massicotte EM, Vaccaro A, Brodke DS, Shaffrey C, Smith JC, Woodard E, Banco RJ, Chapman J, Janssen M, Bono C, Sasso R, Dekutoski M, Gokaslan ZL: Anterior versus posterior surgical approaches to treat cervical spondylotic myelopathy: Outcomes of the prospective multicenter AOSpine North America CSM study in 264 patients. Spine (Phila Pa 1976) 38(26):2247-2252, 2013

12. Fujimori T, Iwasaki M, Okuda S, Takenaka S, Kashii M, Kaito $\mathrm{T}$, Yoshikawa $\mathrm{H}$ : Long-term results of cervical myelopathy due to ossification of the posterior longitudinal ligament with an occupying ratio of $60 \%$ or more. Spine (Phila Pa 1976) 39(1): 58-67, 2014

13. Ghogawala Z, Martin B, Benzel EC, Dziura J, Magge SN, Abbed KM, Bisson EF, Shahid J, Coumans JVCE, Choudhri TF, Steinmetz MP, Krishnaney AA, King JT Jr, Butler WE, Barker FG, Heary RF: Comparative effectiveness of ventral vs dorsal surgery for cervical spondylotic myelopathy. Neurosurgery 68: 622-631, 2011

14. Hirai T, Okawa A, Arai Y, Takahashi M, Kawabata S, Kato T, Enomoto M, Tomizawa S, Sakai K, Torigoe I, Shinomiya K: Middle-term results of a prospective comparative study of anterior decompression with fusion and posterior decompression with laminoplasty for the treatment of cervical spondylotic myelopathy. Spine (Phila Pa 1976) 36(23):19401947, 2011

15. Ikenaga $M$, Mukaida $M$, Nagahara $R$, Yasunaga $T$, Ueda $Y$, Sohma Y: Anterior cervical reconstruction with pedicle screws after a 4-level corpectomy. Spine (Phila Pa 1976) 37(15): E927-930, 2012

16. Iwasaki M, Okuda S, Miyauchi A, Sakaura H, Mukai Y, Yonenobu $\mathrm{K}$, Yoshikawa H: Surgical strategy for cervical myelopathy due to ossification of the posterior longitudinal ligament: Part 1: Clinical results and limitations of laminoplasty. Spine (Phila $\mathrm{Pa}$ 1976) 32(6):647-653, 2007

17. Iwasaki M, Okuda S, Miyauchi A, Sakaura H, Mukai Y, Yonenobu K, Yoshikawa H: Surgical strategy for cervical myelopathy due to ossification of the posterior longitudinal ligament: Part 2: Advantages of anterior decompression and fusion over laminoplasty. Spine (Phila Pa 1976) 32(6):654-660, 2007 
18. Kawano H, Handa Y, Ishii H, Sato K, Oku T, Kubota T: Surgical treatment for ossification of the posterior longitudinal ligament of the cervical spine. Journal of Spinal Disorders 8(2):145-150, 1995

19. Lawrence BD, Jacobs WB, Norvell DC, Hermsmeyer JT, Chapman JR, Brodke DS: Anterior versus posterior approach for treatment of cervical spondylotic myelopathy: A systematic review. Spine (Phila Pa 1976) 38(22 Suppl 1):173-182, 2013

20. Liu X, Min S, Zhang H, Zhou Z, Wang H, Jin A: Anterior corpectomy versus posterior laminoplasty for multilevel cervical myelopathy: A systematic review and meta-analysis. Eur Spine J 23(2):362-372, 2014

21. Luo J, Cao K, Huang S, Li L, Yu T, Cao C, Zhong R, Gong M, Zhou Z, Zou X: Comparison of anterior approach versus posterior approach for the treatment of multilevel cervical spondylotic myelopathy. Eur Spine J 24(8):1621-1630, 2015

22. McCormick WE, Steinmetz MP, Benzel EC: Cervical spondylotic myelopathy: Make the difficult diagnosis, then refer for surgery. Cleve Clin J Med 70(10):899-904, 2003

23. Naderi S, Benzel EC, Baldwin NG: Cervical spondylotic myelopathy: Surgical decision making. Neurosurg Focus 1(6): e1, 1996

24. Ozer AF, Oktenoglu BT, Sarioglu AC: A new surgical technique: Open-window corpectomy in the treatment of ossification of the posterior longitudinal ligament and advanced cervical spondylosis: Technical note. Neurosurgery 45(6):1481-1485, 1999

25. Park MS, Ju YS, Moon SH, Kim TH, Oh JK, Makhni MC, Riew KD: Reoperation rates after surgery for degenerative cervical spine disease according to different surgical procedures: National population-based cohort study. Spine (Phila Pa 1976) 41(19):1484-1492, 2016

26. Sakai K, Okawa A, Takahashi M, Arai Y, Kawabata S, Enomoto M, Kato T, Hirai T, Shinomiya K: Five-year followup evaluation of surgical treatment for cervical myelopathy caused by ossification of the posterior longitudinal ligament: A prospective comparative study of anterior decompression and fusion with floating method versus laminoplasty. Spine (Phila Pa 1976) 37(5):367-376, 2012

27. Sakaura H, Hosono N, Mukai Y, Ishii T, Iwasaki M, Yoshikawa $\mathrm{H}$ : Long-term outcome of laminoplasty for cervical myelopathy due to disc herniation: A comparative study of laminoplasty and anterior spinal fusion. Spine (Phila Pa 1976) 30(7):756759, 2005

28. Sasso RC, Ruggiero RA Jr, Reilly TM, Hall PV: Early reconstruction failures after multilevel cervical corpectomy. Spine (Phila Pa 1976) 28(2):140-142, 2003
29. Saunders RL, Pikus HJ, Ball P: Four-level cervical corpectomy. Spine (Phila Pa 1976) 23(22):2455-2461, 1998

30. Shimizu S, Tanaka R, Rhoton Jr AL: Anatomic dissection and classic three-dimensional documentation: A unit of education for neurosurgical anatomy revisited. Neurosurgery 58(5): E1000, 2006

31. Tani $T$, Ushida $T$, Ishida $K$, lai $H$, Noguchi $T$, Yamamoto $H$ : Relative safety of anterior microsurgical decompression versus laminoplasty for cervical myelopathy with a massive ossified posterior longitudinal ligament. Spine (Phila Pa 1976) 27(22):2491-2498, 2002

32. Thalgott JS, Xiongsheng C, Giuffre JM: Single stage anterior cervical reconstruction with titanium mesh cages, local bone graft, and anterior plating. Spine J 3(4):294-300, 2003

33. Tsuyama N: Ossification of the posterior longitudinal ligament of the spine. Clin Orthop Relat Res 184:71-84, 1984

34. Vaccaro AR, Falatyn SP, Scuderi GJ, Eismont FJ, McGuire RA, Singh K, Garfin SR: Early failure of long segment anterior cervical plate fixation. J Spinal Disord 11(5):410-415, 1998

35. Wang S, Xiang Y, Wang X, Li H, Hou Y, Zhao H, Pan X: Anterior corpectomy comparing to posterior decompression surgery for the treatment of multi-level ossification of posterior longitudinal ligament: A meta-analysis. Int J Surg 40:91-96, 2017

36. Whitmore RG, Schwartz JS, Simmons S, Stein SC, Ghogawala $Z$ : Performing a cost analysis in spine outcomes research: Comparing ventral and dorsal approaches for cervical spondylotic myelopathy. Neurosurgery 70:860-867, 2012

37. Yamazaki A, Homma T, Uchiyama S, Katsumi Y, Okumura $\mathrm{H}$ : Morphologic limitations of posterior decompression by midsagittal splitting method for myelopathy caused by ossification of the posterior longitudinal ligament in the cervical spine. Spine (Phila Pa 1976) 24(1):32-34, 1999

38. Yang $H$, Sun J, Shi J, Shi G, Guo Y, Yang Y: Anterior controllable antedisplacement fusion (ACAF) for severe cervical ossification of the posterior longitudinal ligament: Comparison with anterior cervical corpectomy with fusion (ACCF). World Neurosurg 115:e428-e436, 2018

39. Yonenobu K, Fuji T, Ono K, Okada K, Yamamoto T, Harada $\mathrm{N}$ : Choice of surgical treatment for multisegmental cervical spondylotic myelopathy. Spine (Phila Pa 1976) 10(8):710-716, 1985

40. Yonenobu K, Hosono N, Iwasaki M, Asano M, Ono K: Laminoplasty versus subtotal corpectomy. A comparative study of results in multisegmental cervical spondylotic myelopathy. Spine (Phila Pa 1976) 17(11):1281-1284, 1992 